beam methods and a compilation and discussion of the results obtained. By its clear definition of important lines of future development, it should stimulate research in this field, and by its meticulous attention to experimental detail, it should make easier the task of new research workers who may be attracted to such work.

E. H. S. BURHOP

\section{DIFFUSION AS A MATHEMATICAL PROBLEM}

The Mathematics of Diffusion

By J. Crank. Pp. vi+347. (Oxford: Clarendon Press; London: Oxford University Press, 1956.) 50s. net.

HIS book has been written by a mathematician who has worked on diffusion for a number of years and has compiled many of the available solutions of the diffusion equation. It is a book on applied mathematics in which the problems are stated with the minimum of physical description, the main interest being in the method of solution and in tabulating generalized results. The style of presentation is to be recommended to all those who write for non-mathematicians. The discussion is always closely related to the physical problem in hand, particular examples as well as generalized solutions are given, and purely mathematical questions such as uniqueness of solutions, existence theorems and convergence, except where this concerns numerical calculations, are excluded.

The first six chapters, which treat the case of constant diffusion eoefficient, form a counterpart to "Conduction of Heat in Solids", by Carslaw and Jaeger (Oxford, 1947). At first glance it would appear that this earlier book covers the subject adequately, it being necessary merely to replace thermal diffusivity by diffusion coefficient. However, many results have been given since 1947, the problems being dictated by the boundary conditions of particular experiments on diffusion rather than heat conduction.

In the present work there are two chapters on the related topies of diffusion with a moving boundary, and absorption with chemical reaction. The latter might well have been expanded; for example, nothing is said about absorption with second-order chemical reaction, a problem of physical importance which presents difficulties of a purely mathematical kind.

The remainder of the book deals mainly with variable diffusion coefficients and with numerical methods. These chapters are rather badly arranged, so that chapters on analytical and numerical solutions with variable diffusion coefficients are separated. There is a useful account of methods of finite differences, in which the brief mention of digital computing machines might have been expanded. A valuable chapter deals with the definition and measurement of diffusion coefficients. Here the author restricts himself to a mathematical discussion, the object being to use the analysis to extract the maximum of information from the experimental data. Such discussion is not out of place in this kind of book, but a little more experimental detail would be helpful, since the analysis available, and the type of experiment which is actually carried out, are interdependent.
The primary value of the book will be to research students beginning the study of diffusion. The earlier chapters will also be useful for advanced undergraduate teaching, while the established research worker will welcome the book as a comprehensive survey of the mathematical literature on diffusion during the past ten years.

It is interesting to note that the author is employed in an industrial laboratory. Until quite recently, theoretical books of this kind were always written by academic workers. Presumably industry is at last realizing the valuo of advanced mathematics, and it is to be hoped that more theoretical workers in industry will have time to write books of this quality.

J. F. DAvidoson

\section{EARLY CIVILIZATION IN MESOPOTAMIA}

From the Tablets of Sumer

Twenty-five Firsts in Man's Recorded History. By Dr. Samuel Noah Kramer. Pp. xxv + 293 (40 plates). (Indian Hills, Colorado : Falcon's Wing Press, 1956.) 5 dollars.

GOR more than half a century the Sumerians have Theld an honoured place in history as the creators of urban civilization in the plains of southern Mesopotamia; but it is only during the past two decades that their highly developed poetical literature has become available in translation, and for this we are indebted first and foremost to the labours of Prof. Samuel Noah Kramer. Others had indeed paved the way by the elucidation of the grammar of the Sumerian language-a language unrelated to any known linguistic group - and by the publication of some of the tablets. However, these tablets, most of which were excavated as long ago as the 1890's, were found broken into many fragments, and at the conclusion of the excavations the fragments were divided between the Museum of the Ancient Orient at Istanbul, the University Museum at Philadelphia, and other collections, before any serious attempt had been made to effect joins. As a result, the fragments copied by scholars over a period of some thirty years were rarely large enough to yield intelligible sense.

The great achievement of Prof. Kramer has been due to his recognition that the most urgent need was the reconstruction of the texts of these compositions. With the support of several American learned societies and institutions, he has devoted all his energies to this task, travelling to Europe and Asia, copying unpublished fragments, and identifying those which belong together. The result has been the rediscovery of a lost literature, which deserves to be made known to a wider public than that reached by the learned journals where the first translations have usually appeared.

This is the main purpose which Prof. Kramer has set himself in this book. However, he has not, as in his earlier work, "Sumerian Mythology" (1944), confined himself to a straightforward presentation of the texts. Rather, he has used the texts to illustrate twenty-five different features of Sumerian civiliza. tion, each of which is represented as the earliest known occurrence of a phenomenon familiar in the modern world. These are his "Twenty-five Firsts in Man's Recorded History"-an expression with an oddly academic ring to British ears. Some of these 